\title{
Research on Undergraduate Recessive Ideological and Political Education
}

\author{
Xuehong Zhao
}

Weinan Normal University, Weinan, Shaanxi, 714000

\begin{abstract}
Keywords: College students; recessive ideological and political education; college education
\end{abstract}
\begin{abstract}
Ideological and political education of college students is to improve the overall quality of college students, an important part of building a harmonious society, and ideological and political education in colleges and universities to further improve their relevance, effectiveness and appeal, we can better play its important role in real improvement of college students Ideological and political awareness. However, with the continuous development of undergraduates' awareness of subject and socialization, a single explicit model of ideological and political education is increasingly unable to meet the needs of diversified development and directly affects the effectiveness of ideological and political education. Under this background, as an auxiliary education method of explicit education, implicit education is paid more and more attention by ideological and political education workers, which is further applied to ideological and political education in colleges and universities. The article mainly analyzes the connotation of hidden ideological and political education, summarizes its characteristics and teaching principles, and finally puts forward some specific strategies of implicit ideological and political education.
\end{abstract}

\section{Introduction}

Recessive ideological and political education is the so-called implicit ideological and political education in the process of applying implicit curriculum theory, the development of tacit education resources, through subtle implicit ways to make students unconscious, indirect access to a certain way of thinking, experience or knowledge. Implicit ideological and political education is a relatively direct dominant ideological and political education, so it has the characteristics of indirectness, validity, openness and autonomy. It mainly includes three basic aspects: material form, system form and mental form The main carrier of material form includes the physical environment such as campus planning, architectural design, natural and cultural landscape, and campus ecological environment. The carrier of system form includes the management philosophy contained in the management system and the management means used daily, the carrier of spiritual form mainly includes professional education, teacher demonstration, teacher-student relationship, campus culture and other university spirits. The recessive ideological and political education of undergraduates is a complete system. Among them, the main body of education, the object of education, the carrier of education, the content of education and many other elements form a systematic system of interaction and interaction with each other. In the actual implicit ideological and political education, "educational carrier" is the most prominent element. Through the above specific material forms, institutional forms, spiritual forms and other educational carriers, educational contents are delivered from educational subjects to educational objects.

\section{The general principle of implicit ideological and political education}

The application of implicit education model in college students' ideological and political education should follow the following principles:

In the ideological and political education, most students adopt the method of explicit education and transfer the experience from the teacher to the students according to the established teaching methods so as to help them establish a correct outlook on life, values and world outlook. However, in the traditional dominant ideological and political education model, students are not interested in boring knowledge and stereotyped teaching methods, and even have psychological conflicts that 
directly affect the teaching effect of ideological and political education. The use of tacit education can be knowledge, ideas, experience infiltrated into the daily life of students, learning to go, so that students indirectly, moistens the subtle way of receiving knowledge, can greatly enhance the teaching effectiveness.

As the times are developing, the science and technology are improving, people's opinions of the world and life are constantly changing, and the content of the ideological and political education is characterized by development and dynamics. In particular, with the ever-changing network technology, students get more and more channels of information, various thoughts have more and more notable impact on students 'thoughts and thoughts. Therefore, the students' ideological and political education must follow the principle of dynamics and teachers and students learn from each other, Make progress together. In particular, educators should keep abreast of developments in social development, understand the ideological and psychological characteristics of undergraduates and treat the problems of advancing with the times so as to enhance the pertinence of hidden ideological and political education.

The carrier of education is one of the most prominent elements in the entire system of hidden ideological and political education. Only by continuously enriching the carrier of ideological and political education can it really improve its teaching effectiveness. In particular, the development of new Internet technologies in various networks has led to an increasing proportion of university students applying new media such as QQ, WeChat and Weibo, which provides more channels for higher education to carry out ideological and political education so as to enhance ideological and political education Timeliness and practical effect of education. Such as new media, including pictures, audio, video and other forms, the content of ideological and political education into the new media not only can improve students' interest in learning, and more easily accepted by students.

Compared with other subject knowledge, the ideological and political education has a significant openness, and the students are more active in thinking and new things, more likely to be influenced by external thoughts. The psychology of undergraduates is in a special period of development with strong independence The pursuit of freedom and equality, traditional indoctrination, the role of explicit education is greatly reduced. Therefore, ideological and political education workers should fully take care of the students 'special psychological characteristics, maintain equal relations with the students, respect the students' self-esteem, enhance their learning self-confidence, conduct two-way interactive ideological education with students through the method of recessive education, Highlighting the independent subject status of undergraduates in learning and preventing students from being contradictory and rebellious.

\section{The implicit mode of education in college students' ideological and political education}

In all colleges and universities, the proportion of the courses of ideological and political theory is very small, the teaching hours are small and the contents are numerous, and the effect of classroom teaching is inevitably greatly reduced. However, the proportion of other specialized courses and public courses is also the highlight of higher education. In response to this situation, ideological and political education should make full use of the dominant position of various disciplines, incorporate the ideological and political contents into other disciplines, and use this method as an important way of education of hidden ideas. Ideological and political teachers should strengthen communication and coordination with teachers in other disciplines, so that teachers in other disciplines can change their original concepts of education and integrate the concepts of implicit ideological and political education into the curriculum. Professional education can not unilaterally emphasize the training of students' professional knowledge and skills, and can not obscure the concepts of "ready-made" and "adult". It incorporates the concepts, norms and practices of technical ethics, scientific and technological ethics, and humanistic spirit into professional education so as to realize " Industry, doubts, "the organic combination of professional education as an important carrier of ideological and political education function fully played out.

First of all, to play the latent role of campus culture. As a kind of cultural ideas and spiritual 
achievements recognized by teachers and students in school, campus culture has its own potential characteristics and contains a large number of educational factors. Therefore, it is necessary to make full use of the advantages of campus culture, Material environment, institutional environment and spiritual environment, highlighting its ideological and educational nature, integrating ideological and political education into campus culture, and improving the fun and entertainment of ideological and political education. In addition, we should also strengthen management, improve the rules and regulations of cultural activities in schools, standardize the activities of student associations, and make all kinds of campus cultural activities more standardized. Second, enrich school community activities. Student associations are an important part of college students' work and also an important channel for the reform of ideological and political education in colleges and universities. Community activities reflect the characteristics of knowledge, voluntariness and mass, which can cultivate the pioneering spirit and creativity of college students. It is not only a window for university students to explore knowledge, but also an important way for college students to self-educate. Therefore, colleges and universities should enrich their school social activities, Students are encouraged to cultivate temperament and cultivate correct values in the colorful campus culture. Finally, provide students with more social practice activities. In addition to having social service functions, social practice also possesses moral education and socialization functions. Students learn about society through social practice and enhance their own comprehensive ability and social adaptability. Students through the social activities of the theoretical knowledge of school learning, and in the process affect their ideas and ideas to improve the ideological and moral quality of students. Pay attention to social activities to the greatest extent possible to meet the needs of individual development of students, as far as possible to expand the coverage area in order to better play its moral function.

The popularity of information network technology in college students is getting higher and higher, and the influence of online new media on college students has far surpassed that of traditional media such as television and radio. Therefore, ideological and political education should also keep pace with the times and integrate network media Recessive education process to improve teaching effectiveness. Colleges and universities should continue to innovate the themed websites in the school to enhance the uniqueness and personalization of the websites and arouse the enthusiasm of students to visit the websites. The actual website construction, on the one hand to use teachers and students to build the way, based on a wide range of collegiate opinions to determine the site name, form, specific modules, etc., to improve the scientific website construction, so that students think the site is "Own design website." On the other hand, we should pay attention to the choice and update of the content of the website. We should not only adopt the novel form, but also edit the contents close to the students' thoughts and life, update the website content based on the actual needs and interests of the students, and maintain the continuity of education.

First of all, the ideological and political educators should get rid of the limitations of the traditional educational concepts, update their concepts in time, grasp the psychological characteristics of students through theoretical study and hands-on practice, improve their professional qualities, understand the students' ideological trends, narrow their distance with the students, Narrowing the gap between students and the information in the recessive ideological and political education to grasp the discourse, the initiative. Second, improve the information literacy of ideological and political educators. In the information age, the Internet has the characteristics of synchronicity. Teachers and students almost get the information synchronously. However, in the face of massive information resources, teachers should walk in front of college students and actively deconstruct and construct information. To students, to help students refine the vast amount of online information resources as a hidden resource of creative ideological and political education. Finally, the teacher should keep abreast of the topic of high social attention, as a good opportunity for undergraduate recessive ideological and political education, to guide students to conduct a rational analysis of social hot issues, criticize and guide college students' ethics, non-objective positive, positive The direction of development, the hidden value of the ideological and political education to the full realization of the real value. 


\section{Conclusion}

In short, the ideological and political education reflects the characteristics of the system and complexity. Under the background of economic globalization and social informationization, the ideological consciousness of college students also presents new characteristics that affect the values and outlook on life More diversified, for the ideological and political education of college students put forward higher requirements. At this stage, the development and practice of tacit education in our country are both relatively weak. All educators should combine with the actual conditions of colleges and universities in our country to form a unique thinking of tacit education and improve the effectiveness of ideological and political education. Of course, stressing that recessive ideological and political education does not exclude the dominant position of explicit education and that the actual work should realize the organic combination of recessive education and explicit education complements each other and opens up a new way for more efficient ideological and political work.

\section{References}

[1] Deng Longkui. Journal of Chongqing University of Science and Technology, 2015,4: 182-183 (in Chinese). Necessity and Countermeasures of Implicit Ideological and Political Education in Colleges and Universities [J]. Journal of Chongqing University of Science and Technology, 2015,4: 182-183.

[2] Sun Xiaofeng. A Probe into the Reform of College Students' Ideological and Political Education [J]. Journal of Ideological and Theoretical Education, 2016,7: 64.

[3] Duan Pengfei Necessity of Recessive Education in Ideological and Political Education in the New Period and Its Realization Approach [J]. Political and Ideological Education Research, 2017,25 (2): 52-53.

[4] Xiang Minqing. Probing into the Objective Basis of the Implicit Education Law of Ideological and Political Education [J]. Theory and Exploration, 2014,1: 104-105.

[5] Wang Fengchang. Implicit education in college students' ideological and political education and its innovation [J]. Journal of Yichun University, 2016,33 (7): 161.

[6] Dai Yanjun, Li Tao. Construction of implicit ideological and political education system in colleges and universities [J]. Science and Technology Information, 2016,12 (5), 427-428.

[7] Lin Bohai, Li Jinhong, Song Gang. Analysis of college students implicit ideological and political education model [J] ideological and theoretical education, 2016,3: 81 